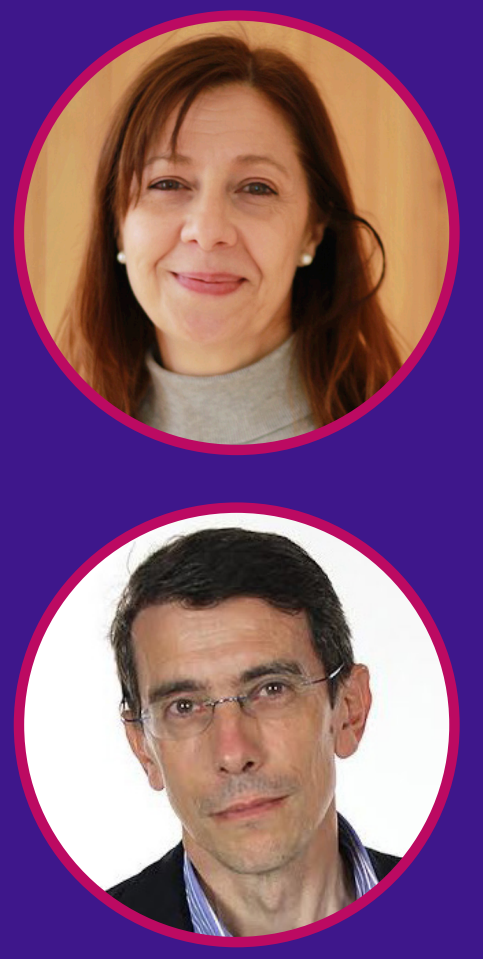

\title{
Los censos e interrogatorios en España como instrumentos de poder en la comunicación política (ss. XVI-XVIII)
}

\author{
Censuses and interrogations as instruments of power in political \\ communication in Spain in the 16th-18th centuries
}

\author{
Dra. Carmen Solano Macías \\ Universidad de Extremadura (España) \\ csolano@unex.es
}

Recibido: 30 de mayo de 2018.

Aceptado: 17 de julio de 2018.

\author{
Dr. Agustín Vivas Moreno \\ Universidad de Extremadura (España) \\ aguvivas@unex.es
}

Received: May 30th 2018.

Accepted: July 17th 2018.

\section{(c) (i) $(-)$ Esta obra está bajo una licencia internacional Creative}

\section{RESUMEN}

Los censos e interrogatorios a la población constituyen un importante instrumento de comunicación política. A partir de esta afirmación, el estudio pretende hacer una revisión histórica de los censos e interrogatorios del Estado en España durante los siglos XVI-XVIII y analizar posteriormente la relación entre información y poder en el Estado ilustrado, época que consideramos de especial interés para analizar los resortes de comunicación política a los que nos referimos.

Palabras-clave: Censos / Interrogatorios / Comunicación política.
ABSTRACT

Censuses and interrogations of the population constitute an important instrument of political communication. With this as our starting point, this study aims to make a historical review of state censuses and interrogations in Spain during the sixteenth to the eighteenth centuries and then analyze the relationship between information and power during the Enlightenment - a time that we consider of special interest to analyze the means of political communication to which we refer.

Key words: Census / Interrogations / Political Communication. 


\section{INTRODUCCIÓN}

$\mathrm{E}$ I Estado siempre ha demostrado tener un inusitado interés por recabar información de sus ciudadanos con la finalidad última de conseguir resortes que le faciliten sus objetivos de control y dominio. En este orden, los sucesivos censos e interrogatorios desarrollados han resultado ser instrumentos de comunicación política de una enorme eficacia para recabar información, racionalizarla y, posteriormente, ejercitar la política y lograr la consecución de los objetivos pretendidos. Información y poder forman, en consecuencia, un binomio que consideramos inseparable en los procesos de comunicación política.

Pretendemos, pues, con esta breve contribución hacer una revisión histórica de los censos e interrogatorios del Estado en España durante los siglos XVI-XVIII y analizar posteriormente la relación entre información y poder en el Estado ilustrado, época que consideramos de especial interés para analizar los resortes de comunicación política a los que nos referimos.

\section{CENSOS E INTERROGATORIOS DEL ESTADO EN ESPAÑA DURANTE LOS SIGLOS XVI- XVIII: HERRAMIENTAS DE COMUNICACIÓN POLÍTICA}

Los censos y los cuestionarios tienen una amplia tradición en España ${ }^{1}$. Los primeros de los que se tiene referencia se llevaron a cabo del siglo XI al XIII, época de los reinos de taifas, cuando se realizan recuentos de población para establecer los tributos que debían pagar cristianos, judíos y musulmanes².

Más tarde, Carlos I mandó hacer un Censo de Pecheros ${ }^{3}$, cuya elaboración comenzó en 1528 y se extendió hasta 1558, aunque los datos siempre estaban referidos a 1527 y 1528 . Cubrió las antiguas provincias -entonces Ilamadas Intendencias- de la Corona de Castilla (excepto el actual País Vasco, que tenía un régimen fiscal propio), el Reino de Granada, las Islas Canarias y el Reino de Navarra; el objetivo de este censo no era el conocimiento de la población en sí, sino actualizar los registros de vecinos pecheros, es decir, de los vecinos que tenían que abonar impuestos o servicios de su Ma- jestad, para recalcular cuánto debían pagar teniendo en cuenta su número y la riqueza de cada lugar. Como es sabido, el clero y la nobleza estaban exentos de este impuesto ${ }^{4}$.

Años después, por iniciativa de Felipe II, se llevaron a cabo unas Averiguaciones sobre diferentes provincias y reinos, mediante cuestionarios realizados en 1574 y 1578, que dieron como fruto las (incompletas) Relaciones histórico-geográfico-estadísticas de los pueblos de España hechas por iniciativa de Felipe $\|^{5}$, por las que se conoce la realidad de la Castilla de la época. Estas averiguaciones consistieron en un conjunto de cuarenta y cinco preguntas o capítulos $^{6}$ que abordaban diversos aspectos de las poblaciones de Castilla: económicos, geográficos, sociales, religiosos, institucionales, etc. El resultado final consistió en ocho volúmenes ${ }^{7}$ que contienen las respuestas de 721 poblaciones de los reinos de Toledo, Murcia y Jaén, y de la provincia de Extremadura $^{8}$.

Aunque este resultado quedó lejos de lo que se pretendía inicialmente, sí resulta de un valor extraordinario para conocer la sociedad, la economía y la vida en la España del siglo XVI.

Complementando las anteriores, Felipe II mandó también realizar un interrogatorio a sus territorios de ultramar, con el objeto de conocerlos con detalle. Resultado de este último son las Relaciones Geográficas de Indias ${ }^{9}$. Para ello, en 1577 se elaboró y envió a las autoridades de los virreinatos un cuestionario de cincuenta preguntas sobre la geografía, mineralogía, botánica, zoología, historia, lengua, costumbres, demografía, economía, etc., de todas las regiones, ciudades, villas y pueblos de las Indias. Con las respuestas al mismo se hicieron la mayoría de las relaciones geográficas ${ }^{10}$. Estas respuestas fueron llegando al Consejo de Indias desde Santa Marta y Venezuela (en 1578), México (1579 y 1580), y Perú (1586), pero no se publicarían hasta tres siglos más tarde ${ }^{11}$.

También fue Felipe II el que, con motivo de la pérdida de la Armada Invencible ${ }^{12}$, dictamina que los vecinos de sus posesiones (esta vez incluyendo a los nobles y a casi todo el clero, además de al pueblo llano, dada la urgencia y necesidad de dinero que se tenía ${ }^{13}$ deben pagar un donativo especial de ocho millones de 
ducados, divididos en seis anualidades, desde 1590 . Aunque al principio se recurrió al Censo de Pecheros de Carlos I, diversos problemas dieron lugar a que, con este único motivo, se llevara a cabo un nuevo censo llamado el Censo de Castilla de 1591 o Censo de los millones ${ }^{14}$. En este censo se recogían los pueblos agrupados por provincias, y se dividía a los vecinos según estados (pecheros, hidalgos, religiosos y clérigos).

Hubo también recuentos de población en el siglo XVII, todavía bajo el reinado de los Austrias, aunque habitualmente han sido descalificados por presentar una información incompleta o defectuosa ${ }^{15}$. Podemos citar, por ejemplo, el Vecindario de la Sal, de 1631, realizado para aplicar un impuesto sobre el consumo de sal que sustituyera a los servicios de Millones; el Vecindario de 1646, que se hizo para el repartimiento de juros; o el Vecindario de Milicias de 1693.

Sin embargo, es en el siglo XVIII, ya con las monarquías borbónicas, cuando se saca partido al sistema de censos y cuestionarios como medio para obtener información fiable. Así, se llevan a cabo varios trabajos con distintos objetivos, que en conjunto reflejan el empeño del Gobierno por conocer el territorio ${ }^{16}$. Revisemos brevemente los sondeos que se llevaron a cabo en esta centuria:

» Vecindario General de España o Censo de Campoflorido (1712-1717) ${ }^{17}$ : se considera el precedente de los censos en España. El obispo de Gironda, que por entonces pertenecía al gobierno del rey Felipe $V$ como Director General de la Real Hacienda, ordena realizar un censo para distribuir equitativamente el pago de los impuestos extraordinarios que se exigieron con objeto de costear la Guerra de Sucesión española (1701-1703). El resultado fue una relación de los vecinos de España ${ }^{18}$, excepto de Vascongadas, Mallorca, Ibiza y Menorca. Es un censo muy criticado por los historiadores, que lo consideran poco riguroso y alejado de las cifras reales $^{19}$. Se calcula que hubo una ocultación de al menos el $25 \%{ }^{20}$, como consecuencia de la motivación tributaria de este censo. Por esta misma razón, sólo se incluían en el vecindario a aquellos que pagaban, quedando excluidos del mismo los nobles e hidalgos, los eclesiásticos y los pobres. Las viudas computaban como medio vecino ${ }^{21}$. En 1717, el Marqués de Campoflorido -Gobernador del Real Consejo de Haciendareclamó el envío de los datos, lo que se hizo en ese mismo año y el siguiente ${ }^{22}$.

» Catastro de Ensenada ${ }^{23}$ : en el reinado de Fernando $\mathrm{VI}$, y bajo la administración del Marqués de la Ensenada, se elaboró un interrogatorio de 41 preguntas (llamadas también artículos 0 capítulos) dirigidas a los representantes de la justicia en los pueblos de Castilla. En la propia encuesta se explicaba detalladamente cómo debía realizarse, qué había que averiguar, etc ${ }^{24}$. Aunque el proceso comenzó en 1740 , la recogida de datos y su procesamiento continuó hasta 1756. Para su realización se creó la Real Junta de la Única Contribución, que dependía directamente del Rey Fernando VI. Este catastro está considerado como el más exhaustivo que se ha hecho en la Corona de Castilla hasta mediados del siglo XVIII. Se llevó a cabo con vistas a una reforma fiscal (que finalmente no se produciría), cuyo objetivo era simplificar los variados impuestos a los que tenían que hacer frente los vecinos, y establecer en su lugar un Impuesto Único, más justo, según las posibilidades que cada vecino tenía. Para ello, se averiguaron los bienes de todos ellos, sin excluir a los eclesiásticos y a los nobles. Cada vecino hacía su declaración de bienes, que era comprobada por peritos de la Administración y cuidadosamente registrada en los libros. Se calculaba el valor fiscal de dichos bienes, y se establecían los estadillos de resumen de cada pueblo y de cada provincia. En general, los datos se consideran fiables, dadas las precauciones y comprobaciones de que fueron objeto. Finalmente, el proceso quedó abandonado definitivamente, tras varios intentos de terminarlo, en el año 1770, ya con Carlos III en el poder. 
Censo de Aranda (1768)25: es el primer censo por habitantes, propiamente dicho (y no por vecinos, familias o fuegos, como en los casos anteriores) de España. Tiene su origen en la orden que el Conde de Aranda, entonces presidente del Consejo de Castilla, envió a los obispos en octubre de 1768, para que, con arreglo a sus instrucciones, formaran un padrón general del vecindario de sus diócesis para conocer con mayor exactitud la población del reino, contando el "número de almas". Su objetivo era, según se indica en el propio censo, "establecer un justo equilibrio en las obligaciones a que concurren y promover ideas útiles al Estado, según sexos y edades". Ciertamente, los habitantes se distribuyen por criterios de edad (se establecieron siete grupos) ${ }^{26}$, sexo y estado civil. Se encomendó la responsabilidad a los obispos, y éstos a su vez encargaron el trabajo a los párrocos de sus diócesis; a éstos se les envió una plantilla que debían cumplimentar con datos que iban desde información sobre el obispado, la localidad, datos demográficos, y veintiocho cuestiones relacionadas con el número de eclesiásticos, conventos, hospitales, mercados, aldeas, etc. La mayor parte de las respuestas son del año 1768. Una vez recibidas estas respuestas por diócesis, se enviaron a la Secretaría de la Presidencia de Castilla, donde se conservaron ${ }^{27}$.

» Encuesta de Tomás López ${ }^{28}$ : es una serie de 16 preguntas que confeccionó el geógrafo Tomás López, dirigidas oficialmente a los obispos, curas párrocos y funcionarios civiles, solicitando datos del territorio de sus parroquias u obispados; se planteó de esta forma porque, en algunos lugares, los eclesiásticos eran los únicos que sabían leer y escribir. Se solicitaba, además de las respuestas a las preguntas planteadas, que aportaran un pequeño mapa para completar la información. El objetivo de la encuesta era realizar el Diccionario Geográfico de España, que Tomás López inició en 1776, y que, debido a su fallecimiento, no pudo terminar.
»Censo de Floridablanca29: fue realizado bajo la dirección de Don José Moñino y Redondo, Conde de Floridablanca, de 1786 a $1787^{30}$, durante el reinado de Carlos III. Está considerado como el censo español más completo y fiable de la época moderna. Abarcó todo el territorio nacional, proporcionando datos sobre la estructura de la población por sexo, edad, estado civil y situación económica de todas las localidades españolas. Esta vez, la responsabilidad de Ilevarlo a cabo se encargó a las autoridades civiles, aunque ayudadas por las eclesiásticas. Este censo tiene unas características que le confieren modernidad estadística, como la universalidad (incluye todo el territorio y a todos los individuos de la nación), la uniformidad en la elaboración, y la contemporaneidad en la recogida de la información (los datos se recogen y elaboran con mucha rapidez, de forma que, un año después de comenzar, estaban listos los resultados). Además, declaraba en principio una finalidad primordialmente demográfica y estadística, y prometía el anonimato de los individuos encuestados, como se hace hoy día mediante el secreto estadístico. Pero, en el fondo, subyacen, además de los manifestados, otros motivos menos idealistas y más pragmáticos ${ }^{31}$, como el reclutamiento militar o el negado interés fiscal. Y, de hecho, el anonimato no se respetó en muchos lugares.

» Interrogatorio de la Real Audiencia de Extremadura: se realizó en todas las poblaciones extremeñas en 1791, a consecuencia del establecimiento en Cáceres de la Real Audiencia de Extremadura. Estaba compuesto por 57 preguntas.

Censo de Godoy ${ }^{22}$ (1797): último censo del siglo XVIII, sigue el mismo sistema que el Censo de Floridablanca, manteniendo a grandes rasgos su estructura, pero mejorando los fallos que aquel presentaba; así,las clasificaciones son más depuradas: subdivide la población mayor de 50 
años en seis grupos, cuando en recuentos anteriores constituía sólo uno. La clasificación por ocupaciones es más extensa (por ejemplo, divide a los artesanos en tres categorías: maestros, oficiales y aprendices), etc. Presenta los datos de la población por intendencias o provincias de la época, incluyendo una relación completa de los pueblos que las formaban. Sus informes son, en general, más detallados. La idea era crear un proyecto de continuidad, pero la invasión de España por las tropas napoleónicas lo impidió.

En el siglo XIX continuarán realizándose distintos censos, llegándose en 1856 a la creación de la Comisión General de Estadísticas del Rei$\mathrm{no}^{33}$, que realizaría censos institucionales rigurosos y periódicos. Todos estos elementos aportaron al Gobierno la información necesaria para llevar a cabo sus tareas con eficacia; si bien en algunas ocasiones las respuestas son ambiguas, o incluso falsean claramente la realidad, en conjunto proporcionan, como ya hemos apuntado, una nítida imagen de la vida real de los ciudadanos de la España moderna.

En relación con la importancia que tiene para el Estado recoger información sobre sus súbditos, vamos a revisar a continuación la conexión que existe entre la información y el poder en el contexto en el que nos movemos.

\section{INFORMACIÓN Y PODER EN EL ESTADO ILUSTRADO}

"La información no es el cuarto poder, ni siquiera un puro instrumento de poder. La información es el poder [...] Es un instrumento de las clases dirigentes ${ }^{\prime 34}$. Este texto de A. Sánchez-Bravo resume la importancia de la información, tanto en el presente como en tiempos pasados.

Según Rodríguez Cancho, en el siglo XVIII el Estado llustrado concibe el poder como un proceso de racionalización y concentración, que produce información, pero también la exige, y que necesita recabar dicha información para ejercer la política que le va a permitir la consecución de sus objetivos ${ }^{35}$.
Pues bien, una de las formas de obtener información es la realización de censos o interrogatorios a la población. Como hemos comentado más arriba, en la primera época de los censos (la llamada Época Primitiva, hasta mediados del siglo XVIII) el objetivo principal de éstos era fiscal. Sin embargo, a finales de este mismo siglo, los interrogatorios generales a la población no tienen una sola finalidad: se busca obtener información sobre los súbditos en aspectos muy variados, para posteriormente aplicar este conocimiento a los propósitos que fueran necesarios. Por tanto, podemos decir que el propósito de estos cuestionarios era el deseo y la necesidad del Estado de conocer a sus súbditos para poder gobernarlos. Así, se recaban conocimientos que sirvan para administrar el territorio de forma eficaz, buscando la mejora de las condiciones de vida de los ciudadanos, fin característico de la ideología ilustrada que acompaña la Edad Moderna; pero también se perseguía la consecución del poder efectivo sobre los súbditos. Son pues, instrumentos de comunicación entre el estado y sus súbditos con el objeto de racionalizar la acción política, esto es, instrumentos de comunicación política.

De esta forma, la información y el poder forman un binomio inseparable: el Estado no puede ejercer su soberanía sobre lo que no conoce, y por ello, uno de sus intereses fundamentales en la época moderna fue obtener datos sobre sus habitantes; algunos de carácter básico, como su número, estado civil, edades, bienes y profesiones; pero también sobre otros adicionales, como su formación, condiciones de vida, creencias, el estado de los pueblos y ciudades que habitaban, de las tierras que cultivaban, del ganado que criaban, de sus de sus posadas y caminos, industrias, abastos, rentas, etc.

Dicha información proporcionaba los instrumentos necesarios para ejercer la autoridad del Rey desde la capital de la nación hasta las aldeas más remotas, principalmente a través de una red de funcionarios (consejos, intendentes, corregidores, escribanos...). Así, conociendo al detalle las posibilidades de cada población, se podían recaudar impuestos, reclutar soldados para el ejército del país, etc. Por esta causa, no era extraño que los encargados de responder a los cuestionarios en representación de sus pueblos (alcaldes, regidores, párrocos, etc.) falsearan datos en sus respuestas, sospe- 
chando que proporcionar información veraz podría ser, al cabo, perjudicial para sus propios intereses y los de sus convecinos.

Esta tendencia de las autoridades locales a adulterar la información era conocida por los encargados de realizar los censos o interrogatorios, de forma que éstos buscaban la forma de minimizarla. Para ello utilizaban métodos variados: a veces mandaban encuestadores "a calle hita", es decir, haciendo visitas personales casa por casa, preguntando directamente a los vecinos. 0 enviaban visitadores a cada pueblo, con la facultad (además de ver por sí mismos el entorno) de revisar los documentos personalmente y de interrogar -incluso en secreto- a quienes considerasen conveniente. Otra forma de soslayar el falseamiento de las respuestas "oficiales" era remitir las mismas preguntas a autoridades civiles y al párroco de una misma población: en muchas ocasiones las respuestas, totalmente distintas, proporcionaban una imagen real de la situación del municipio ${ }^{36}$.

Sin embargo, como decimos, los fines "beneficiosos" para la población también estaban presentes: conociendo el territorio, el gobierno podía intentar mejorar sus condiciones de vida, poniendo en marcha mecanismos para repartir equitativamente los impuestos, hacer justicia evitando abusos de los personajes o de las facciones locales más poderosas, o proteger a los agricultores de la dominación de la Mesta y de las arbitrariedades de los señores.

En cualquier caso, unos y otros propósitos se encaminaban hacia un objetivo final: facilitar el gobierno del Rey sobre su territorio y afianzar su poder. La información se obtenía del pueblo, pero los poseedores de la misma eran los estamentos más altos de la nación: el Estado y sus instituciones eran los receptores de los datos recabados, que una vez interpretados se convertían en información. El uso unívoco de ésta era lo que proporcionaba el poder a las autoridades.

Por otra parte, hemos de tener en cuenta que tanto en este momento histórico como hoy día- muchos de los aspectos relacionados con los procesos de lectura y de escritura tenían una clara relación con la información, y por consiguiente con el poder. Varias son las vertientes informativas que podríamos extraer.
De entre las distintas vertientes que incluye la cultura escrita, una de las que más influencia tenía en este sentido era la enseñanza: solo las personas con formación en lectura y escritura podían sacar partido de la información, analizarla y utilizarla para defender sus intereses. La falta de formación, por el contrario, genera indefensión y vulnerabilidad ${ }^{37}$. Así pues, la instrucción educativa era una condición previa imprescindible para acceder a la información.

En España, durante el periodo ilustrado, se buscaba potenciar el acceso de los niños (sobre todo del sexo masculino) a la formación básica, es decir, a los rudimentos de lectura y de escritura. Se consideraba que éstos eran necesarios para favorecer el respeto a la autoridad y a las leyes, así como para el desarrollo correcto del trabajo que llevarían a cabo en el futuro y, en suma, para la evolución de la sociedad. Sin embargo, no se veía con tan buenos ojos el acceso del pueblo llano a otros estudios más avanzados (los que hoy llamamos secundarios y sobre todo los universitarios), que debían estar restringidos ${ }^{38}$.

Las razones que sustentaban esta actitud negativa de las autoridades ante la formación "excesiva" del pueblo eran varias:

» Se corría el riesgo de desabastecer de fuerza de trabajo los sectores productivos (agricultura, ganadería, minería...) y saturar los improductivos (religiosos, escribanos, etc.) ${ }^{39}$

» Se quería mantener el statu quo que sostenía el Antiguo Régimen, de forma que los estamentos privilegiados eran los únicos que podían acceder a la educación, y con ella a la información necesaria para proteger sus prerrogativas

» Se consideraba arriesgado proporcionar a los ciudadanos conocimientos suficientes como para poner en cuestión el orden establecido. La llegada de noticias de la reciente revolución acaecida en Francia, con las terribles consecuencias que tuvo para los sectores privilegiados influyó, con seguridad, en este sentido. 


\section{CONCLUSIONES}

En consecuencia de todo lo dicho tres podrían ser las conclusiones a las que llegamos tras nuestro estudio:

1. Los censos e interrogatorios se configuran como instrumentos de comunicación política usados por el Estado con el objeto de recopilar información para su posterior instrumentalización como resorte de poder.

2. La comunicación política habida a través de los mencionados censos e interrogatorios resulta ser necesaria para la propia formalización del Estado Moderno. Éste se configura como una estructura jurídica e institucional de poder que tiene en la información política una de sus bases sustanciales. En otras palabras, la información, esto es la comunicación política, y el poder son elementos directamente vinculados.
3. Los censos e interrogatorios pueden ser utilizados como instrumentos de análisis histórico. Son fuentes que directamente nos ofrecen datos e informaciones de personas y lugares como si de una foto fija se tratara-, e indirectamente nos posibilitan el estudio de contexto y su representación, naturalmente en conjunción con otras fuentes históricas. En otros términos, los instrumentos de comunicación política se configuran como herramientas del análisis histórico. I

\section{NOTAS}

1 MELGAR GARCÍA, M., BARRIONUEVO OLMOS, A. Censos de población en España: una larga tradición. Revista Índice, Noviembre 2009, pp. 7-10.

2 INSTITUTO NACIONAL DE ESTADÍsTICA. Los primeros censos españoles [en línea]. Disponible en: http://www.ine.es/explica/explica_ historia_censos.htm (Consulta: 28/05/2018)

3 Los documentos originales resultantes de este Censo se encuentran en el Archivo de Simancas, con la signatura Contadurías Generales, no 768. El Instituto Nacional de Estadística ha publicado en dos volúmenes una transcripción revisada y ordenada de este legajo, que recoge resúmenes de los informes y comentarios a los mismos: Censo de pecheros de Carlos I. Madrid: Instituto Nacional de Estadística, 2008.

4 El Censo de Pecheros ha sido tratado en numerosos trabajos, como en los de: CARANDE TOVAR, R. Carlos V y sus banqueros. BarceIona: Crítica, 2000. CARRETERO ZAMORA, J.M. La Averiguación de la Corona de Castilla, 1525-154: los buenos vecinos pecheros y el dinero del reino en época del emperador Carlos V. Valladolid: Junta de Castilla y León, 2009; Los servicios de las Cortes de Castilla en el siglo XVI. Cuadernos de Historia Moderna, no 21, 1998, pp. 15-58. GARCÍA ESPAÑA, E., MOLINIÉ-BERTRAND, A. (eds.) Censo de Castilla de 1591, t. 2. Estudio analítico. Madrid: Instituto Nacional de Estadística, 1985- 1986. GONZÁLEZ, T. (ed.) Censo de población de las provincias y partidos de la Corona de Castilla en el siglo XVI. Valladolid: Maxtor, 2009 (edición facsímil de la obra publicada por 
la Imprenta Real en 1829). MARTíN GALÁN, M. Fuentes y métodos para el estudio de la demografía histórica castellana durante la Edad Moderna. Hispania, 1981, no 148, pp. 231-325. MOLINIÉ-BERTRAND, A. Au siècle d'Or. L'Espagne et ses homme: la population du Royaume de Castille au XVI siècle. Paris: Economica, 1985. PÉREZ MOREDA, V. El crecimiento demográfico español en el siglo XVI. En: Jerónimo Zurita, su época y su escuela. Zaragoza: Institución Fernando el Católico, 1986, pp. 55-71. RUIZ MARTíN, F. La población española al comienzo de los tiempos modernos. En: Cuadernos de Historia. Anexo de la revista Hispania, vol.1, 1967, pp. 189-202; Los dineros de Carlos V. En: Carlos V: Centenario de Carlos V (1500- 2000). Madrid, 2000, pp. 7-11. VINCENT, B. Récents travaux de démographie historique en Espagne (XIVe-XVIIle siècles). En: Annales de Démographie Historique, 1977, pp. 463-491.

5 Relaciones topográficas de Felipe II. Madrid: Consejo Superior de Investigaciones Científicas, Departamento de Publicaciones, 1993. También existe un resumen de las mismas, elaborado por J. Ortega Rubio en 1918 y en la actualidad de acceso público en línea (http:// sirio.ua.es/libros/BEducacion/relaciones_topograficas/thm0000.htm ; consulta: 17/01/2015). Sobre estas Relaciones, nos parece de interés el estudio realizado por CAMPOS Y FERNÁNDEZ DE SEVILLA, F.J. Las relaciones topográficas de Felipe II: índices, fuentes y bibliografía. Anuario jurídico y económico escurialense, no 36, 2003, pp. 439-574, que además del estudio bibliográfico, incluye el cuestionario y el índice de pueblos. Otros trabajos al respecto son: CATALINA, J., PÉREZ VILLAMIL, M. Relaciones topográficas de España. En: Memorial Histórico Español. Madrid: Real Academia de la Historia, 1903; MIGUÉLEZ, M. Relaciones histórico-geográficas de los pueblos de España. En: Catálogo de los códices españoles de la Biblioteca de El Escorial, I. Relaciones históricas. Madrid: Imprenta Helénica, 1917-1925, pp. 251-332; VIÑAS MEY, C. Las relaciones de Felipe II y su publicación. En: Estudios Geográficos, no 42, 1951, pp. 131-136. VIÑAS MEY, C., PAZ, R. Relaciones histórico-geográfico- estadísticas de los pueblos de España, hechas por iniciativa de Felipe II. Reino de Toledo. Madrid: CSIC, 1951; ALVAR EZQUERRA, A. Estudio introductorio a las Relaciones Topográficas de Felipe II. Madrid: Instituto de Estudios Madrileños, 1993; ARROYO LLERA, F. Las relaciones geográficas y el conocimiento del territorio en tiempos de Felipe II. Estudios geográficos, vol. LIX, no 231, 1998, pp. 169- 200; Agua, paisaje y sociedad en el siglo XVI, según las Relaciones Topográficas de Felipe II. Madrid: Ediciones del Umbral, 1998. Además, existen numerosos estudios sobre aspectos concretos de estas Averiguaciones: obras pías, religión, etc., o sobre poblaciones o regiones determinadas.

6 En realidad, hubo tres intentos de realizar este interrogatorio, variando el número de preguntas en cada uno de ellos. Así, en el primer intento, de 1574, las preguntas fueron 24. En el segundo, en 1578, fueron 59. Y en el último, también en 1578, se enviaron 45. Los pueblos que habían respondido anteriormente quedaban exentos de hacerlo en el siguiente intento, aunque algunos respondieron, aun así, a más de un cuestionario.

7 Los volúmenes originales se conservan en la Biblioteca del Monasterio de San Lorenzo de El Escorial, y existen copias de los mismos, realizadas en el S. XVIII, en la Biblioteca de la Real Academia de la Historia.

8 Se han publicado algunos trabajos sobre las relaciones topográficas de Felipe II en Extremadura, entre los que se encuentran: ARIAS GONZÁLEZ, L. La visión popular de la historia y el pasado en las Relaciones Topográficas de Extremadura. Revista de estudios extremeños, vol. 49, no 1, 1993, pp. 47- 64; PEREIRA IGLESIAS, J.L. Las relaciones topográficas de Felipe II en Extremadura. Norba, no 6, 1985, pp. 175-178; ARIAS GONZÁLEZ, L., MARTíN, H., CHOCARRO MARTíN, F.J. Relaciones topográficas de Salamanca y Extremadura (1574). Salamanca: revista de estudios, no 35-36, 1995, pp. 325-338.

9 SOLANO, F. de (ed.) Cuestionarios para la formación de las Relaciones Geográficas de Indias: siglos XVI-XIX. Madrid: CSIC, 1988. CARRERA STAMPA, M. Relaciones geográficas de Nueva España, siglos XVI y XVIII [en línea]. Estudios de Historia Novohispana, no 2 , 1968, pp. 233-261. Disponible en: http://www.historicas.unam.mx/publicaciones/revistas/novohispana/pdf/novo02/0024.PDF (Consulta: $28 / 05 / 2018)$

10 No obstante, hubo otros cuestionarios durante el reinado de Felipe II, fechados en 1569 y 1571, en los que variaba sustancialmente el número de preguntas.

11 Entre 1881 y 1897, el americanista español Marcos Jiménez de la Espada publicó las Relaciones Geográficas de Indias en cuatro volúmenes, que se refieren principalmente a Perú ; más tarde, entre 1905 y 1906, el mejicano Francisco del Paso y Troncoso publicó, en la segunda serie de Papeles de Nueva España, siete volúmenes sobre geografía y estadística de Méjico. Sobre este tema se puede consultar: ÁLVAREZ PELÁEZ, R. La conquista de la naturaleza americana. Madrid: CSIC, 1993; BUSTAMANTE, J. El conocimiento como necesidad de estado: las encuestas oficiales sobre Nueva España durante el reinado de Carlos V. Revista de Indias, vol. LX, no 218, 2000, pp. 33-55; RIVERA REYES, V. La importancia de las relaciones geográficas en el español de América. En: El español de América: actas del VI Congreso Internacional de El español de América, Tordesillas, Valladolid, 25-29 de octubre de 2005. Valladolid: Diputación de Valladolid, 2007, pp. 1125-1131; MARZAL, M.M. Historia de la antropología indigenista: México y Perú. Barcelona: Anthropos; Mérida: Editora Regional de Extremadura, 1993; MORA FIGUEROA, D., TASCÓN, I.G. Las relaciones topográficas de Castilla y Geográficas de Indias de Felipe II. En: Felipe II: los ingenios y las máquinas. Madrid: Sociedad Estatal para la Conmemoración de los Centenarios 
de Felipe II y Carlos V, 1998; MUNDY, B.E. The Mapping of New Spain: Indigenous Cartography and the Maps of the Relaciones Geográficas. Chicago: The University of Chicago Press, 1996; VILAR, S. La trajectoire des curiosités espagnoles sur les Indes: trois siècles de Interrogatorios et Relaciones. Melanges de la Casa de Velázquez, vol. VI, Paris, 1970, pp. 247- 308.

12 La formación y pérdida de la Armada Invencible fue el principal motivo, pues fue lo más costoso. Pero hubo otros, todos de tipo militar: las luchas contra berberiscos y turcos, la batalla de Lepanto, la represión de las sublevaciones moriscas en la península y de las revueltas calvinistas en los Países Bajos. Véase: Censo de la Corona de Castilla de 1591 [en línea]. Disponible en: http://www.madrid. org/iestadis/fijas/estructu/general/otros/descarga/eh1591me.pdf (Consulta: 06/03/2014)

13 Se excluyó del pago (no del censo) a la orden mendicante de los Franciscanos; en cuanto al clero regular, gozaban de ventaja, pues diez religiosos contaban como un vecino. Véase: INSTITUTO NACIONAL DE ESTADÍSTICA. La estadística en la historia [en línea]. Disponible en: http://www.ine.es/explica/docs/historia_censos.pdf (Consulta: 06/03/2014)

14 El manuscrito original del llamado Censo de los Millones se custodia en el Archivo de Simancas. Ha sido editado por el INE en dos tomos: el primero se llama Vecindarios de 1591, y recoge la relación de los pueblos, de los vecinos y los religiosos. El segundo es un completo estudio analítico del censo y del entorno en que se realizó. GARCÍA ESPAÑA, E., MOLINIÉ BERTRAND, A. (eds.) Censo de Castilla de 1591. Madrid: Instituto Nacional de Estadística, 1985-1986.

15 LANZA GARCÍA, R. El vecindario de 1683: una fuente inédita para el estudio de la población de la Corona de Castilla. Revista de Historia Económica, vol. 23, no 2, pp. 335-369. Encontramos un estudio global de la población española en el siglo XVII en: FERNÁNDEZ VARGAS, V. La población española en el siglo XVII. En: La crisis del siglo XVII: la población, la economía, la sociedad. Madrid: Espasa Calpe, 1989, pp. 1-156. También en: NADAL OLLER, J. (coord.) La evolución demográfica bajo los Austrias: Actas del II Congreso de la Asociación de Demografía Histórica, Alicante, abril de 1990. Alicante: Instituto de Cultura Juan Gil-Albert, 1991. Y analizando algunos de los censos del XVII: SÁNCHEZ BELÉN, J. A. Absolutismo y fiscalidad en Castilla a fines del siglo XVII: el encabezamiento general del reino (1682-1685). Espacio, Tiempo y Forma, Serie IV, Historia Moderna, no 2, 1989, pp. 175-218; y, del mismo autor: La política fiscal en Castilla durante el reinado de Carlos II. Madrid: Siglo XXI, 1996.

16 De ellos habla, en un interesante trabajo, RODRÍGUEZ CANCHO, M. Interrogatorios del siglo XVIII: estudio comparativo. Norba: revista de arte, geografía e historia, no 2, 1981, pp. 221-232.

17 La edición más reciente del vecindario es: Censo de Campoflorido. Madrid: Instituto Nacional de Estadística, 1996. Uno de los mejores conocedores de este censo es el profesor Francisco BUSTELO GARCÍA DEL REAL, de quien podemos consultar: El vecindario general de España de 1712-1717 o Censo de Campoflorido. Revista Internacional de Sociología, vol. XXXII, no 7-8, 1973, pp. 83-103; y vol. XXXIII, no 11-12,1974, pp. 7-35; La población española en la segunda mitad del siglo XVIII. Moneda y crédito, no 123, 1972, pp. 53-104; La transformación de vecinos en habitantes: el problema del coeficiente. Revista de estudios geográficos, no 130, 1973, pp. 154-164.

18 Sus cifras fueron comentadas pocos años después de la realización del Censo por Gerónimo de Uztáriz, en Therórica y práctica de comercio y marina. Madrid, 1724

19 BUSTELO, F. El vecindario general de España... (op. cit.), p. 84.

20 En Extremadura la ocultación fue de un 35\%. Así lo afirma MELÓN JIMÉNEZ, M.A. Extremadura en el Antiguo Régimen: Economía y sociedad... (op. cit.), p. 31

21 PENA GIMENO, J. El vezindario de Campoflorido. Cuadernos de Geografía, no 39-40, 1986, p. 313- 330.

22 Por ello lleva el nombre de Vecindario de Campoflorido, aunque quien lo mando hacer fue el obispo de Gironda, cinco años antes. Véase: GARCÍA ESPAÑA, E. Censos de población españoles... (op. cit.), pp. 463-464.

23 El Ministerio de Educación, Cultura y Deportes mantiene en su portal web una completa sección dedicada al Catastro de Ensenada, donde, además de una breve presentación y estudio del mismo, se da la posibilidad de acceder a los documentos originales escaneados -algunos en malas condiciones, lo que dificulta, e incluso imposibilita su lectura- tanto de las preguntas como de las respuestas obtenidas. Asimismo, se permite la búsqueda por nombres de las localidades, se informa de la localización de los originales, y se aporta una bibliografía sobre el tema. Disponible en: http://pares.mcu.es/Catastro/servlets/ServletController. Por otra parte, el Instituto Nacional de Estadística (INE) ha publicado en cuatro tomos el Censo de la Corona de Castilla del Marqués de la Ensenada: año de 1752 (Madrid: INE, 1994) que incluye el propio Censo (constituido por las clasificaciones de la población realizadas por las Contadurías Principales de las Intendencias (tomos I y III), y también aportaciones del INE para facilitar el manejo y comprensión de la obra (tomos II y IV). Entre los trabajos a los que podemos recurrir para encontrar más información sobre dicho catastro, destacamos los 
realizados por Concepción CAMARERO BULLÓN: CAMARERO BULLÓN, C. (dir.) Colección Alcabala del Viento: según las Respuestas Generales del Catastro de Ensenada. Madrid: Tabapress y Centro de Gestión Catastral y Cooperación Tributaria, 1990-1997 (80 títulos); Madrid y su provincia en el Catastro de Ensenada. I. La Villa y Corte, 1750-1759. II. Los pueblos de Madrid, 1750-1759. Madrid: Ediciones del Umbral, 2001-2006; El Catastro de Ensenada: magna averiguación fiscal para alivio de los Vasallos y mejor conocimiento de los Reinos. 1749-1756. Madrid: Ministerio de Hacienda, Dirección General del Catastro, 2002; Antecedentes en el siglo XVIII de las tareas acometidas por la Comisión de Estadística General del Reino (1858-1870). En: Jornadas Científicas: 150 Aniversario de la creación de la Comisión de Estadística General del Reino. Madrid: INE, 2007, pp. 141-192. Y otros como: MATILLA TASCÓN, A. La Única contribución y el Catastro del Marqués de la Ensenada. Madrid: Ministerio de Hacienda, Servicio de Estudios de la Inspección General, 1947. RODRÍGUEZ VILLA, A. Don Cenón de Somodevilla, Marqués de la Ensenada: ensayo biográfico formado con documentos en su mayor parte originales, inéditos y desconocidos. Madrid: Librería de M. Murillo, 1878. También son frecuentes los estudios por provincias basados en este Catastro, como por ejemplo: GALLEGO DOMÍNGUEZ, O. El Catastro de Ensenada en la provincia de Orense: Catálogo. Madrid: Ministerio de Cultura, 1988; JIMÉNEZ SERRANO, B., SERRANO GUTIÉRREZ, J.M. El Catastro del Marqués de la Ensenada en el antiguo Reino de Granada. Granada: Junta de Andalucía, Consejería de Cultura, 2004.

24 Respuestas generales del Catastro del Marqués de la Ensenada [en línea]. Madrid: Ministerio de Educación, Cultura y Deporte. Disponible en: http://pares.mcu.es/Catastro/servlets/ServletController (Consulta: 28/05/2018)

25 Censo del Conde de Aranda 1768 [en línea]. Madrid: Instituto Nacional de Estadística, 2001-2011. Disponible en: http://www.ine.es/ sS/Satellite?L=es_ES\&c=INEPublicacion_C\&cid=1259948726844\&p=1254735110606 \&pagename=ProductosYServicios\%2FPYSLayout\&tittema=Publicaciones+hist\%C3\%83\%C2\%B3ricas (Consulta: 25/06/2014). Encontramos que la bibliografía sobre el Censo de Aranda es abundante en cuanto a estudios aplicados a poblaciones o provincias concretas, más que al propio censo en general. Citamos, por ejemplo, los siguientes estudios: JIMÉNEZ DE GREGORIO, F. La población de las Islas Canarias en la segunda mitad del siglo XVIII. Anuario de estudios atlánticos, no 14, 1968, pp. 127- 301; La población de la provincia de Madrid en el Censo de Aranda. Anales del Instituto de Estudios Madrileños, no 10, 1974, pp. 229-256. VILAR RAMÍREZ, J.B. El censo de Aranda en el Obispado de Orihuela: aproximación a la demografía valenciana moderna. Anales de Historia Contemporánea, no 1, 1982, pp. 271-277. PÉREZ SARRIÓN, G. EI censo de Floridablanca en Aragón: un análisis general. Revista de Historia Económica, no 2, 1984, pp. 263-286. VILAR RAMÍREZ, J.B., INIESTA MAGÁN, J. El Censo de Aranda en el Obispado de Cartagena (1769): aproximación a la demografía española moderna. Anales de Historia Contemporánea, no 3, 1984, pp. 231-235.

26 Los grupos por edad eran: Párvulos: hasta 7 años; medianos: de 7 a 16; mayores de 16 hasta 25; mayores de 25 hasta 40; mayores de 40 a 50; mayores de 50 años. En cuanto a estado civil, sólo diferencia entre solteros y casados, sin tener en cuenta a los viudos, que incluye entre los primeros. Así lo afirma CAMACHO BELLO, J. La población del Arzobispado de Toledo en los tiempos modernos [en línea]. Madrid: Universidad Complutense de Madrid, 1999, p. 62. Disponible en: http://biblioteca.ucm.es/tesis/19972000/H/0/ H0054001.pdf (Consulta: 12/11/2014)

27 Sin embargo, la mayor parte de la documentación original se ha perdido, aunque la correspondiente a algunos obispados (como los de Plasencia, Córdoba o parte del de Toledo, donde se incluye Madrid) se conserva en el Archivo Histórico Nacional. Afortunadamente, se guardan copias de los originales realizadas en el mismo siglo XVIII en la Real Academia de la Historia. CAMACHO BELLO, J. La población del Arzobispado de Toledo... (op. cit.)

28 La bibliografía sobre Tomás López es extensa, especialmente a partir del segundo centenario de su muerte en 2002. Sobresalen, entre otros, los estudios de LÍTER MAYAYO, C. Tesoros de la cartografía española. Madrid: Biblioteca Nacional, 2001; La obra de Tomás López: imagen cartográfica del siglo XVIII. Madrid: Biblioteca Nacional, 2002; y, de la misma autora en colaboración con SÁNCHEZ BALLESTER, F.: Tomás López y sus colaboradores. Madrid: Biblioteca Nacional, 1998. Asimismo, son de interés los trabajos de: MARCEL, G. El geógrafo Tomás López y sus obras: ensayo de biografía y de cartografía. En: Boletín de la Real Academia de la Historia, no LIII, 1908, pp. 452-453; MANSO PORTO, C. El interrogatorio de Tomás López: nueva hipótesis sobre su finalidad. En: Historia, clima y paisaje: estudios geográficos en memoria del profesor Antonio López Gómez. Valencia: Universidad de Valencia, 2004, pp. 175-186; SAN ANTONIO GÓMEZ, A., MANZANO AGUGLIARO, F., LEÓN CASAS, M.A. Tomás López: un cartógrafo de gabinete del siglo XVIII: fuentes y método de trabajo. En: XVII Congreso Internacional de Ingeniería Gráfica. Sevilla, 2005 pp. 1-10

29 El Instituto Nacional de Estadística ha publicado una edición facsímil de este censo: Censo español executado de órden del Rey comunicada por el Excelentísimo señor Conde de Floridablanca, Primer Secretario de Estado y del Despacho, en el año de 1787. Madrid: INE, 1980. Asimismo, ha editado seis volúmenes con los datos obtenidos en las distintas circunscripciones de la época, que aparecen también agrupados según las actuales provincias y comunidades autónomas: Censo de 1787 de Floridablanca. Madrid: INE, 1980. Para mayor información sobre este censo, citamos algunos de entre los numerosos trabajos publicados sobre el mismo: DOPICO, F., 
ROWLAND, R. Demografía del Censo de Floridablanca: una aproximación. Revista de Historia Económica, vol. VIII, no 3, 1990, pp. 591618; GARCÍA SESTAFE, J.V. La realización del Censo de Floridablanca. En: La población española en 1787: II Centenario del Censo de Floridablanca: Actas del Congreso Histórico Nacional, Murcia, 16-19 de Diciembre de 1987. Madrid: INE, 1992, pp. 66-77 (Esta monografía recoge, además, otras ponencias de gran interés sobre el Censo de Floridablanca, como la de EIRAS ROEL, A. El Censo de 1787 como fuente para el estudio regional de la estructura de la población y de la familia, o la de LIVI BACCI, M. El censo de Floridablanca en el contexto de los censos europeos). Citamos también los trabajos de: JIMÉNEZ DE GREGORIO, F. La población de la actual provincia de Madrid en el Censo de Floridablanca (1786). Madrid: Consejería de Educación, Juventud y Deporte, 1980; RUIZ ALEMÁN, J. Floridablanca: escritos políticos: la instrucción y el memorial. Murcia: Academia Alfonso X El Sabio, 1982; PÉREZ

30 Por tanto, en fechas muy próximas al Interrogatorio de la RAE en Extremadura, que se llevó a cabo en 1791.

31 Véase: PÉREZ MOREDA, V. La estadística demográfica... (op. cit.), pp. 11-12, donde el autor manifiesta que el motivo de declarar abiertamente que las motivaciones no eran de orden fiscal, tenía como fin evitar las respuestas falseadas de los pueblos, que solían ocultar bienes y disminuír cifras para evitar ser esquilmados. Así se manifiesta en la Real Orden de 25 de julio de 1786, que figura en la Advertencia del Censo publicado: "que temerosos los Pueblos de las quintas, o aumento de las contribuciones, ocultan las noticias y disminuyen el número...”.

32 El Instituto Nacional de Estadística ha publicado una edición facsímil del Censo de Godoy, editado en su día por la Imprenta Real: Censo de la población de España de el año 1797 executado por orden del Rey en el de 1801. Madrid: INE, 1994. Lamentablemente, la documentación primaria del censo se ha perdido, así como los antecedentes. Así se afirma en: GARCíA ESPAÑA, E. Censos de población españoles... (op. cit.), p. 485. Para obtener información general sobre este Censo, remitimos, por ejemplo, a RUIZ ALMANSA, J. EI censo de la población de España de 1797. Revista Internacional de Sociología, vol. 5, no 19, 1947, pp. 233-247; o a PÉREZ MOREDA, V. En defensa del Censo de Godoy: observaciones previas al estudio de la población activa española de finales del siglo XVIII. En: Historia económica y pensamiento social: estudios en homenaje a Mateo del Peral. Madrid: Alianza Editorial, 1983, pp. 283-299. Hay además numerosos trabajos que toman como base los datos obtenidos de este censo, pero ya referidos a un tema o lugar concreto, como por ejemplo: LASPALAS PÉREZ, F.J. La escolarización elemental en España según el Censo de Godoy. Historia de la Educación, no 10, 1991, pp. 203-226. NAVARRO, A. V., PUERTO, J.S. Estado de la educación en Tenerife a finales del siglo XVIII. Revista de educación, no 339, 2006, pp. 661-691.

33 En 1857 cambia su nombre a Junta de Estadística, y en 1873 a Instituto Geográfico y Estadístico.

34 Véase SÁNCHEZ-BRAVO CENJOR, A. La editorialización de la información. En: Información, política y cultura. Cursos de verano El Escorial. Madrid: Universidad Complutense de Madrid, 1989, p. 79-90.

36 Los dos últimos métodos que se nombran son utilizados en el Interrogatorio de la Real Audiencia, como veremos más adelante.

37 ARRIBA GONZÁLEZ DE DURANA, A. (coord.). Políticas y bienes sociales: procesos de vulnerabilidad y exclusión social. Madrid: Fundación FOESSA, 2008, p. 397.

38 RUIZ RODRIGO, C., PALACIO LIS, I. Pauperismo y educación, siglos XVIII y XIX: apuntes para una historia de la educación social en España. Valencia: Universidad de Valencia, 1995.

39 El propio ilustrado Pedro de Olavide veía inadecuado que accediesen a la Universidad personas de cualquier clase social, pues creía perjudicial que los jóvenes abandonasen la agricultura o los talleres artesanos familiares para cursar estudios superiores. Véase: OLAVIDE, P. Plan de estudios para la Universidad de Sevilla. Barcelona: Ediciones de Cultura Popular, 1969, pp. 91-92. 